\title{
To Study the Adequacy Assessment of Chitradurga distribution substation using MCS
}

\author{
Shruthi.M ${ }^{1}$, S.B.Karajgi ${ }^{2}$ \\ PG Scholar, Department of Electrical and Electronics, SDMCET, Dharwad, India ${ }^{1}$ \\ Professor, Department of Electrical and Electronics, SDMCET, Dharwad, India ${ }^{2}$
}

\begin{abstract}
Power system has dynamic behavior as it faces various disturbances like sudden variation in load, sudden variation in generation and different faults. Due to the variation of load demand, the operation, maintenance and control of power system have become a challenging task. To meet the load requirements, many noticeable research activities are going on in the field of deregulation, restructuring of power system, utilization of renewable energy sources and installing small generators at the load centre referred to as Distributed Generation (DG) etc. Furthermore, among many different types of DG units, renewable DG units are widely accepted. In this paper, adequacy evaluation of the $220 \mathrm{kV}$ distribution system with DG has been proposed. This concept deals with installation of additional capacity with the existing capacity for supplying load, which is provided by renewable DG units. Reliability index such as average unsupplied load (AUL) is calculated using Monte Carlo simulation (MCS).
\end{abstract}

Keywords: Adequacy Assessment, Renewable wind energy, MCS, IPP, Distribution system, Distributed generation.

\section{INTRODUCTION}

The basic function of a power distribution system is to supply customers with electrical energy as economical as possible. The reliability performance of the power distribution system plays an important role. For reliability assessment, the system is divided into three hierarchical levels. $1^{\text {st }}$ level (HL1) consists of evaluation of generation system, $2^{\text {nd }}$ level (HL2) consists of combined evaluation of generation and transmission systems, $3^{\text {rd }}$ level (HL3) consists of combined evaluation of all the main sectors of power system (Generation, Transmission and Distribution system). Due to the complexities in HL3, only distribution system is taken into account for analysis of reliability evaluation of power system. Fig 1 represents hierarchical levels of reliability assessment.

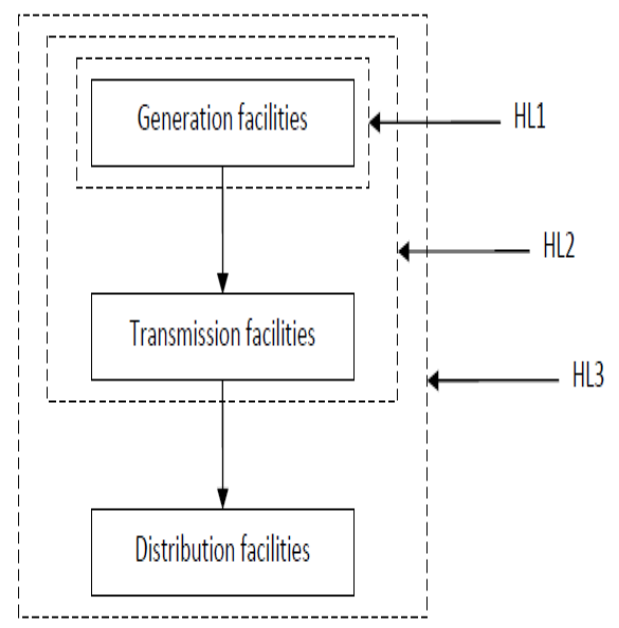

Fig 1: Hierarchical levels for reliability assessment

The reliability assessment of a distribution system can be evaluated by two attributes: adequacy and security. Adequacy evaluation specifies the ability of the system to supply the accumulated electrical energy requirements of customers within component ratings and voltage limits, even when scheduled and unscheduled component outages occur. Security evaluation specifies to the ability of power system to withstand the disturbances arising from faults or equipment outages. Most of the research work is carried out considering security as an aspect of reliability evaluation with DG and only a few are operated considering adequacy requirement.

Adequacy assessment can be operated using either an analytical technique or the Monte Carlo method. Many papers involving analytical techniques have been proposed. Present paper focuses on operation of the Monte Carlo method in distribution system adequacy assessment.MCS can be considered to be more superior to an analytical approach in situations, which cover, for example, the subsequent considerations.

1. Time reliant or sequential issues are considered.

2. The duty cycle of peak units are modeled.

3. Non exponential component state duration distributions are considered.

4. Distributions of reliability indices are required.

5. A large unacceptable set of states (unfeasible range) in multi- area generation system studies is involved.

Quantitative reliability assessments not only prefer the actual physical elements in a system in terms of their function and random behavior, but also perceive overall system operating conditions. The indices determined should be easily understandable and it should easily interpret. There are many techniques and resulting indices are applicable in the adequacy assessment of power systems.

All the techniques are commonly classified into two section, Analytical methods and Monte Carlo simulation methods. A mathematical and probabilistic model has been modeled in form of equation in analytical method 
and typically enumerates and combines the probabilities endure the randomness of power generation in wind and frequencies of system states to arrive at the reliability turbines. indices. A Monte Carlo simulation delights the problem as a series of substantive experiments, the result depend on the operating characteristics of the system. The reliability indices are then predicted by performing number of experiments, universally reliability evaluation of engineering system focus on analytical methods but MCS used as an alternative solution.

Distributed generation (DG) is commonly used in smallscale (1 KW-50 MW) electric power generators that produce electricity at a site close to customers or that are connected to an electric distribution system. It includes combustion gas turbines, fuel cells, solar, wind turbine and electric vehicles etc.

Due to the improvements in distributed generation technology, some amount of spare capacity is also added at the customer sites. DG assures sufficient and acceptable continuity of supply, in the event of failure in the Generation, Distribution, and Transmission systems.

The degree of redundancy has to be proportionate with the requirement, that the supply should be as profitable as possible. It is necessary that maximum reliability is achieved within a given set of economic constraints. DG units are closer to customers so that transmission and distribution costs are avoided or reduced. It is straight forward to find sites for small generators than for large ones.

This paper abode the random nature of the distribution system operation when DG units are operating laterally within the system. Based on load requirement DG are manage to operate, the mechanism of turning on and off each DG unit will be a random process. The random on and off cycle of each DG will result in a random contribution of this DG to the system overall power capacity. Therefore, the overall system power capacity will vary randomly and the determination of this capacity requires proper modeling of the random operation state of the system.

\section{PROBLEM FORMULATION}

In this section, adequacy evaluation of an electrical distribution system with DG is described. The assumptions considered are,

1. Renewable DG used is wind power generation.

2. Hourly load characteristic of Distribution system is known a priory.

3. Due to future load growth, distribution systems may not be able to supply required load and hence additional energy is required. To avoid expansion of substation, DG installed close to them.

The interpretation of ability of a distribution system for satisfying the total system load is done as a part of adequacy assessment. Certainly the average amount of energy not supplied is given as adequacy index. MCS is used for distribution system adequacy assessment to
The subsequent control strategies are applied throughout the study

- Unit power factor is maintained for all wind based DG.

- Wind-based DG output power is regulated and used for satisfying load. Extra energy will be stepped up to grid.

- All DG ratings are considered in Million units.

\section{DESCRIPTION OF THE MONTE CARLO METHOD FOR ADEQUACY ASSESSMENT}

In MCS a random value is selected for each of the tasks, based on the range of estimates. The model is predicted based on this random value. The outcome of MCS are recorded and performed for different random values. A typical MCS calculates the model hundreds or thousands of times, every time using distinct randomly generated values. The random values can be generated with the help of some random generators. After completion of simulation large number of results are obtained from the model, each value based on random input values.

A. Algorithm for Adequacy Calculation

Step 1: Consider peak load data of simulated year

Step 2: Select DG as Wind Generator

Step 3: Calculate AUL indices without adding DG.

Step 4: For with DG, Add substation power with IPP power expressed as

$$
\mathrm{P}_{\mathrm{S}}=\mathrm{P}_{\mathrm{T}}+\mathrm{P}_{\mathrm{DG}}
$$

Where $P_{T}$ is substation power, $P_{D G}$ is IPP generated power, $\mathrm{P}_{\mathrm{S}}$ is the Total power with $\mathrm{DG}$.

Step 5: Calculate Average unsupplied load as indices.

During AUL calculation the energy from the substation $\left(\mathrm{P}_{\mathrm{T}}\right)$ curve is superimposed on the peak load curve of substation, to obtain the available margin. A positive margin reveals that the substation generation is sufficient to meet the substation load, although a negative margin reveals that the substation demand is not satisfied, extra energy is required to fulfill the demands. The average amount of the unsupplied load during each year (AUL) is estimated by running MCS for a large number of sample years and using the following equation:

AUL $=\left|\frac{\sum \text { Negative Margin in MW }}{8760 * \mathrm{M}}\right|$

$\mathrm{M}$ is the number of Monte Carlo experiments.

\section{STUDY AREA}

For the adequacy analysis 220/66/11kV SRS Chitradurga distribution substation of state electricity board has been selected. The main supply for this network comes from $440 \mathrm{kV}$ station located at Guttur and from 440kV PGCIL. Substation consists of five power transformers, three are of $220 / 66 \mathrm{kV} 100 \mathrm{MVA}$, other two transformer is of $66 / 11 \mathrm{kV} 12.5 \mathrm{MVA}$. The two $220 \mathrm{kV}$ incoming lines from Guttur and PGCIL step down voltage at $66 \mathrm{kV}$. The $66 \mathrm{kV}$ bus transmits power to Hiriyur, Challakere, Turuvanur, Chitradurga and Holakere $66 \mathrm{kV}$ Substation. 
INTERNATIONAL JOURNAL OF INNOVATIVE RESEARCH IN ELECTRICAL, ELECTRONICS, INSTRUMENTATION AND CONTROL ENGINEERING

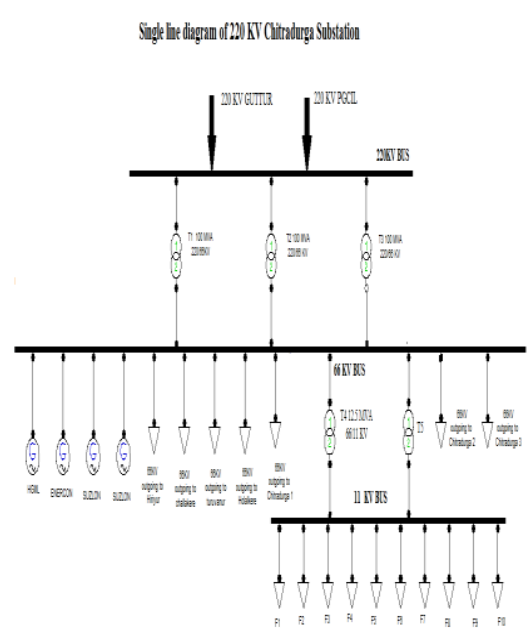

Fig 2: Single line diagram of 220/66/11 kV SRS Chitradurga substation.

The Power from Chitradurga substation is delivered through two 12.5 MVA $66 / 11 \mathrm{kV}$ transformers to 10 feeder. This Substation consists of all protective devices and measuring meters and The Independent power production (IPP) from different companies like Suzlon, Enercon, HGML, FIZA, Micon, Jindal, Pioneer, Reliance, NSL Jagallur, and Pallagata are connected to substation. Figure 2 shows the single line diagram of 220/66/11 kV SRS Chitradurga substation. For the study purpose Chitradurga $66 \mathrm{kV}$ Substation is chosen for adequacy analysis. The single line diagram of $66 \mathrm{kV}$ substations is shown in figure 3 . The $66 \mathrm{kV}$ Chitradurga bus is step down the voltage at $11 \mathrm{KV}$ by using the two $66 / 11 \mathrm{kV}$ transformer. Each transformer has $12.5 \mathrm{MVA}$ rating. The $11 \mathrm{KV}$ bus feed the power to 10 different feeders. The details of feeder are presented in table 1. The three IPP HGML, Suzlon, Enercon have been connected. The total consumption data required for simulation is shown in table 2 and the collected data is from 2014 year. Simulation model have been developed in MATLAB software.

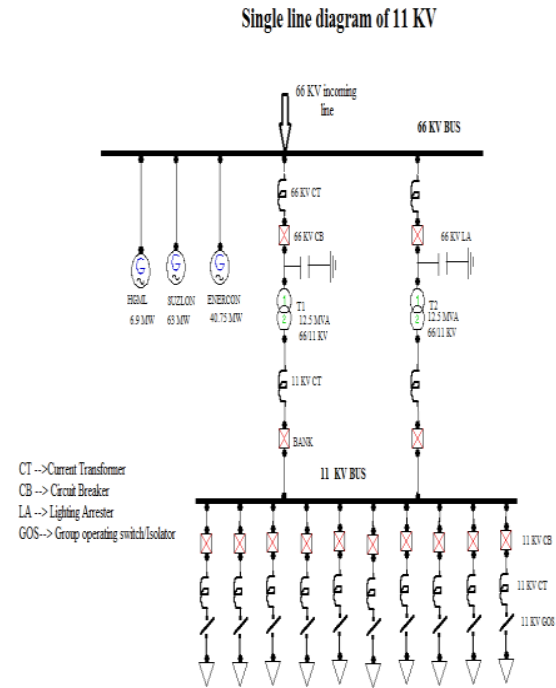

Fig 3. Single line diagram of $66 \mathrm{kV}$ Chitradurga substation.

\begin{tabular}{|l|l|}
\hline Number & Feeder name \\
\hline F1 & COPPER MINES \\
\hline F2 & KYADIGERE \\
\hline F3 & J.N. KOTE \\
\hline F4 & KASAVARATTI \\
\hline F5 & AUX. TRANSFORMER 1 \\
\hline F6 & AUX. TRANSFORMER 2 \\
\hline F7 & PALLAVAGERE \\
\hline F8 & STADIUM \\
\hline F9 & INDUSTRIAL AREA \\
\hline F10 & SARASWATHIPURAM \\
\hline
\end{tabular}

The analysis of the case study is done in two phases. In the first phase, the adequacy assessment is performed on only its substation capacity. In the second phase, the distributed generation is included in the analysis.

\section{Phase I: Analysis without DG}

This phase is concerned with the estimation of the available substation capacity of the distribution system in the absence of the DG. The goal of this phase is to decide, whether the substation received power will be enough to cover the demand of the system all year round or there is a need for a substation expansion. To achieve this goal Energy from grid is subtracted with Total energy consumption. The details are shown in table 2 . From the figure 4 it is clear that the system encountered several hours where the substation energy is not enough to satisfy the required demand, and therefore, there is a need for an increase of the overall substation available capacity

\begin{tabular}{|c|c|c|}
\hline Month & $\begin{array}{c}\text { Energy from } \\
\text { grid (MU) }\end{array}$ & $\begin{array}{c}\text { Total energy } \\
\text { consumption } \\
\text { (MU) }\end{array}$ \\
\hline January & 31.635 & 69.5034 \\
\hline February & 47.2242 & 63.1324 \\
\hline March & 43.6347 & 69.27218 \\
\hline April & 39.3214 & 55.6192 \\
\hline May & 15.9246 & 35.4214 \\
\hline June & 3.421 & 46.8582 \\
\hline July & 1.245 & 44.3739 \\
\hline August & 4.431 & 33.5051 \\
\hline September & 8.7314 & 34.7726 \\
\hline October & 13.7823 & 27.485 \\
\hline November & 14.247 & 33.8494 \\
\hline December & 29.3672 & 50.7654 \\
\hline
\end{tabular}

Table2. Energy from grid and Total Energy Consumption.

This result, shows a high insufficiency of the substation in each month, which is not meeting system load and cannot be used to assess the system adequacy because the analysis was performed for one sample year.

During this sample year, the energy from substation is considered to be a random variable (80 to $100 \%$ of nominal values). Therefore, different margin patterns will be expected for different sample years. 
In order to estimate average amount of the unsupplied load Phase II: Analysis with DG

for any sample year, MCS was performed for a large In this phase, DG units are run in parallel with the existing number of sample years. The average amount of substation. The total energy generated from IPP is given in unsupplied load for each year was calculated using (2). table 3. In order to calculate total available power, $\mathrm{P}_{\mathrm{T}}$ is Fig. 5 portrays the Monte Carlo convergence process. The superimposed on the available $P_{D G}$ (IPP energy) to average unsupplied load (AUL) is estimated to be 25.879 determine the overall $\mathrm{P}_{\mathrm{S}}$, in this study $\mathrm{P}_{\mathrm{T}}$ is the energy from MU/year. This figure reflects the great need for substation the grid, $\mathrm{P}_{\mathrm{DG}}$ is the energy from IPP. $\mathrm{P}_{\mathrm{S}}$ is the total energy. capacity increase and the inadequacy of the system in its current structure to meet the installed demand. In the later section, the effects of running some DG in parallel with the existing substation are explained.

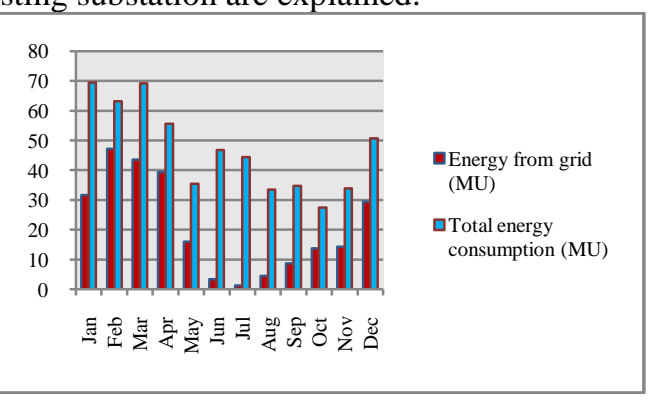

Fig 4: Grid energy and Total energy consumption.

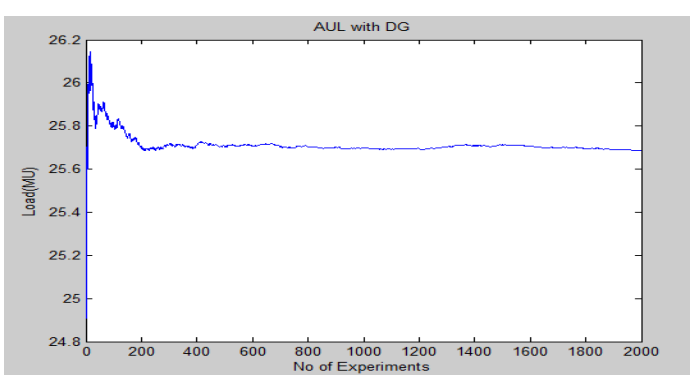

Fig.5. AUL is $25.879 \mathrm{MU}$

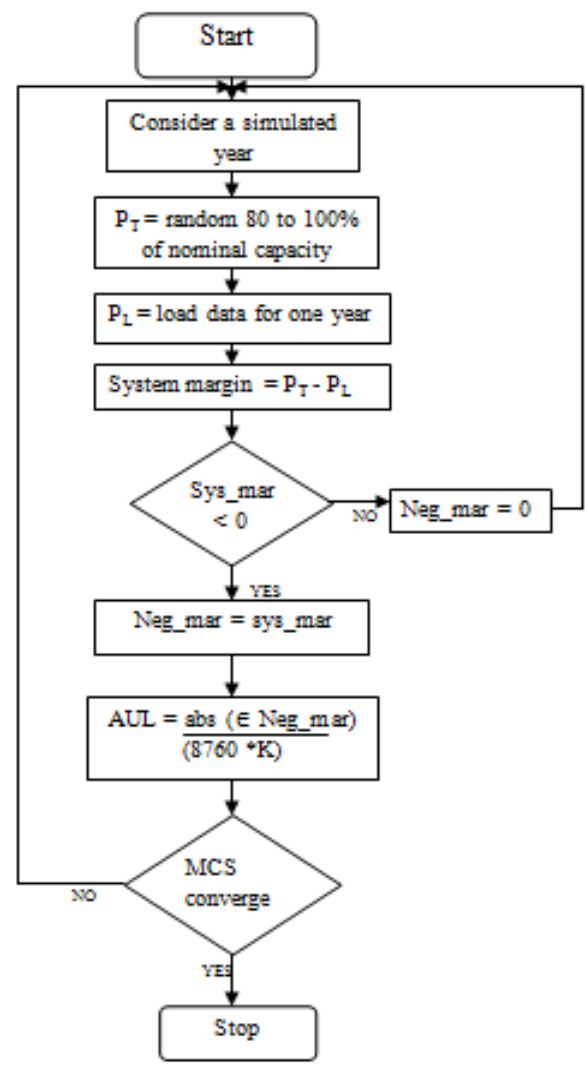

Fig 6.Flow chart for calculating AUL

\begin{tabular}{|c|c|}
\hline \multicolumn{2}{|c}{$\mathrm{P}_{\mathrm{S}}=\mathrm{P}_{\mathrm{T}}+\mathrm{P}_{\mathrm{DG}}$} \\
Month & $\begin{array}{c}\text { Total ipp } \\
\text { generation } \\
\text { (MU) }\end{array}$ \\
\hline Jan & 41.763 \\
\hline Feb & 18.018 \\
\hline Mar & 26.406 \\
\hline April & 19.262 \\
\hline May & 29.204 \\
\hline June & 66.741 \\
\hline July & 100.21 \\
\hline Aug & 61.34 \\
\hline Sep & 53.366 \\
\hline Oct & 22.328 \\
\hline Nov & 33.06 \\
\hline Dec & 21.857 \\
\hline
\end{tabular}

Table 3: Total IPP Generation from Enercon, Suzlon, HGML

\begin{tabular}{|c|c|c|c|}
\hline Month & $\begin{array}{c}\text { Energy from } \\
\text { Grid+ IPP } \\
\text { generation } \\
(\mathrm{MU})\end{array}$ & $\begin{array}{c}\text { Total energy } \\
\text { consumption } \\
(\mathrm{MU})\end{array}$ & $\begin{array}{c}\text { Extra Energy } \\
\text { to Grid } \\
\text { (MU) }\end{array}$ \\
\hline Jan & 73.398 & 69.5034 & 3.8946 \\
\hline Feb & 65.2421 & 63.1324 & 2.1097 \\
\hline Mar & 70.0406 & 69.2721 & 1.1257 \\
\hline April & 58.5833 & 55.6192 & 2.9692 \\
\hline May & 45.129 & 35.4214 & 10.0534 \\
\hline June & 70.162 & 46.8582 & 23.3054 \\
\hline July & 101.45 & 44.3739 & 57.4034 \\
\hline Aug & 65.771 & 33.5051 & 32.0657 \\
\hline Sep & 62.0978 & 34.7726 & 28.3589 \\
\hline Oct & 36.1103 & 27.4857 & 8.4478 \\
\hline Nov & 47.307 & 33.8494 & 13.9569 \\
\hline Dec & 51.2241 & 50.7654 & 0.4587 \\
\hline
\end{tabular}

Table 4: with DG power and extra energy

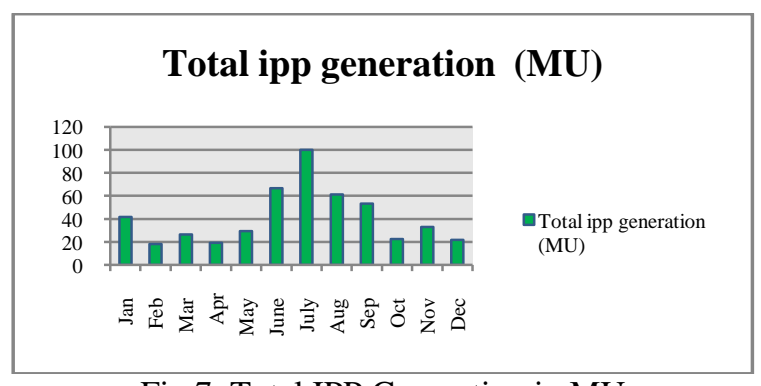

Fig.7. Total IPP Generation in MU

The comparison between the values with DG and without DG, Reveal that, DG running parallel with the substation has eliminated most of the negative margins during the 
2014 year. However, the criteria to judge the adequacy of the system in this case are still the AUL per year. In this substation extra energy generated will be exported to grid. Hence if $5 \%$ Uncertainty occurs in the generation AUL is shown in figure 8 and it is estimated by running Monte Carlo simulation and similar procedure is carried out for different uncertainty. The details are shown in table 5.

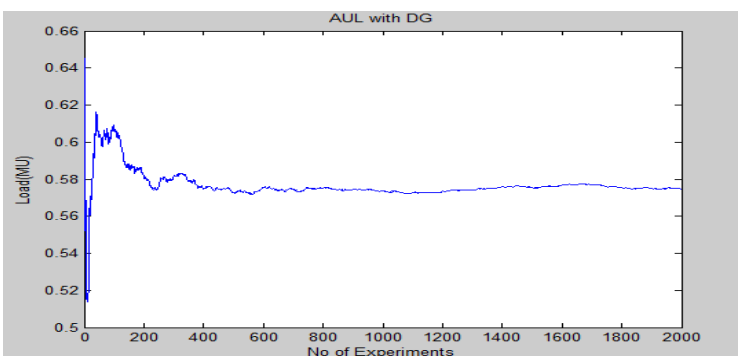

Fig 8: AUL with $5 \%$ Uncertainty is $0.5876 \mathrm{MU}$.

\begin{tabular}{|c|c|}
\hline Uncertainty (\%) & AUL (MU) \\
\hline 5 & 0.587 \\
\hline 10 & 1.317 \\
\hline 20 & 5.556 \\
\hline 30 & 9.457 \\
\hline
\end{tabular}

Table 5: Different ranges of Uncertainty

The conclusion drawn directly from this result is that distributed generation units, if well managed, can give a good support to the existing system.

\section{CONCLUSION}

In this work adequacy evaluation of the distribution system has been performed by considering wind energy based DG. Monte Carlo simulation technique is used for calculation of adequacy index. Application of the proposed approach for real system notifies that wind energy based distributed generation can provide positive margin and could be a very good value addition to minimize the curtailment of unsupplied load value as distribution system adequacy.

\section{ACKNOWLEDGEMENTS}

The authors are grateful to KPTCL, SRS Chitradurga Substation for providing relevant data used in the study. We also sincerely appreciate the support of the entire staff of 220/66/11 kV SRS Chitradurga substation.

\section{REFERENCES}

[1] R. Billinton, "Reliability Assessment of Large Electric Systems", Kluwer Academic Press/Springer India,2008.

[2] R. Billinton, H. Chen, and R. Ghajar, "A sequential simulation technique for adequacy evaluation of generation. systems including wind energy" IEEE Trans. Energy Convers., vol. 11, no. 4, pp. 728-734,Dec. 1996

[3] Tautiva, C., Cadena A.: "Optimal placement of distributed generation on distribution networks", in Proc. 2008 IEEE/PES, Trans. and Dist. Conf., 2008, pp. 1-5.

[4] Willis, H.L.: "Analytical methods and rules of thumb for modeling DG distribution interaction", Proc. IEEE Power Engineering Society Summer Meeting, Seattle, USA, 16-20 July 2000, pp. 164344

[5] Hegazy,Y.H.Salama, M.M.A.etal.:"Adequacy assessment of distributed generation systems using Monte Carlo simulation", IEEE Trans. Power Syst., 2003, pp. 48-52.
[6] R. Karki and P. Hu,: "Wind power simulation model for reliability evaluation", in Proc. IEEE Can. Conf. Electr. Comput. Eng., Saskatoon, May 1-4, 2005, pp. 541-544.

[7] Alhajri, El-Hawary, M.E.: "Optimal distributed generation sitting via fast sequential quadratic programming", in Proc. 2007.

[8] Hu, X. Zhao, Xu Cai and J. Shang, "Simulation of a hybrid wind and gas turbine system," DRPT2008 Nanjing China, 6-9 April 2008, 2482-2486(2008).

[9] P. A. Daly and J. Morrison, "Understanding the potential benefits of distributed Generation on power delivery systems," in Proc. Rural Electric Power Conf., 2001, pp. A2/1-A2/13.

\section{BIOGRAPHIES}

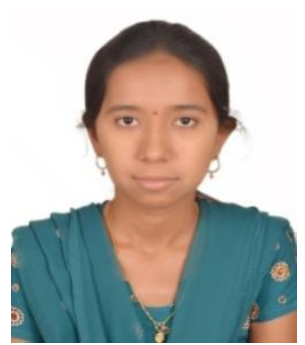

Miss.Shruthi.M, PG Scholar, Department of Electrical \& Electronics Engineering in SDMCET, Dharwad. She obtained her BE from DBIT Bangalore 2012.Presently she is pursuing her Master's Degree in Power System Engineering. Her field of interest includes distribution system reliability analysis, renewable energy, probabilistic analysis of power systems and power quality issues.

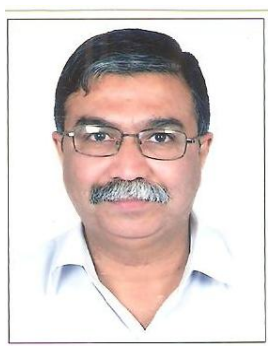

Dr.S.B.Karajgi is currently working as a Professor in Department of Electrical \& Electronics Engineering, SDMCET, Dharwad. He obtained his BE from KUD 1981, M.Tech from REC Warangal 1987 and Ph.D from NITK Surathkal 2014. He has published a number of papers in National and International Journals and Conferences. His research interest includes Power and energy systems, operation and control of electric distribution systems, Distribution system design and control, reliability evaluation of power systems. 